University of New Hampshire

University of New Hampshire Scholars' Repository

8-2008

\title{
Evaluating Children's Advocacy Centers' Response to Child Sexual
}

\section{Abuse}

Theodore P. Cross

University of New Hampshire - Main Campus

Lisa M. Jones

University of New Hampshire - Main Campus, lisa.jones@unh.edu

Wendy A. Walsh

University of New Hampshire - Main Campus, wendy.walsh@unh.edu

Monique Simone

University of New Hampshire - Main Campus

David Kolko

University of Pittsburgh - Main Campus

See next page for additional authors

Follow this and additional works at: https://scholars.unh.edu/soc_facpub

Part of the Child Psychology Commons, and the Civic and Community Engagement Commons

\section{Recommended Citation}

Cross, Theodore P.; Jones, Lisa M.; Walsh, Wendy A.; Simone, Monique; Kolko, David; Sczepanski, Joyce; Lippert, Tonya; Davison, Karen; Crynes, Arthur; Sosnowski, Polly; Shadoin, Amy L.; and Magnuson, Suzanne, "Evaluating Children's Advocacy Centers' Response to Child Sexual Abuse" (2008). Juvenile Justice Bulletin. 106.

https://scholars.unh.edu/soc_facpub/106

This Article is brought to you for free and open access by the Sociology at University of New Hampshire Scholars' Repository. It has been accepted for inclusion in Sociology Scholarship by an authorized administrator of University of New Hampshire Scholars' Repository. For more information, please contact Scholarly.Communication@unh.edu. 


\section{Authors}

Theodore P. Cross, Lisa M. Jones, Wendy A. Walsh, Monique Simone, David Kolko, Joyce Sczepanski, Tonya Lippert, Karen Davison, Arthur Crynes, Polly Sosnowski, Amy L. Shadoin, and Suzanne Magnuson 


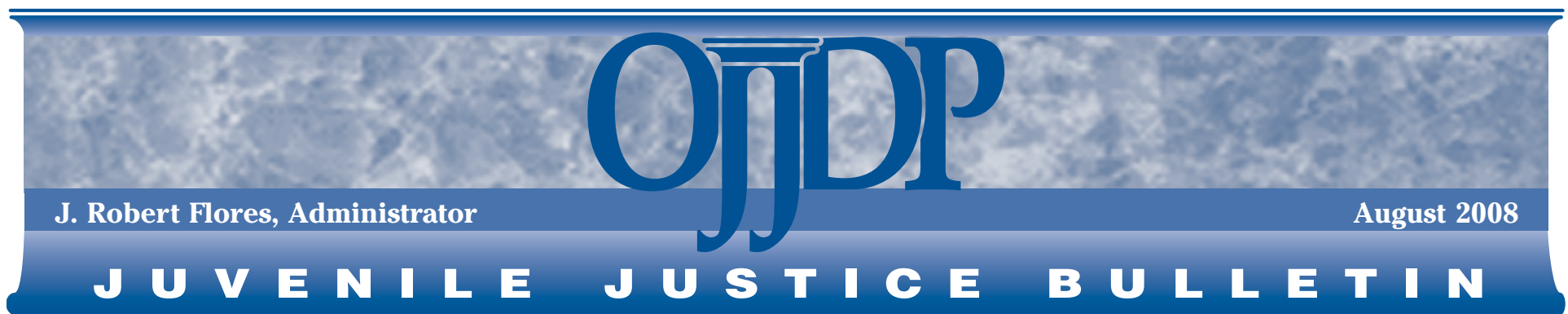

\section{Evaluating Children's Advocacy Centers' Response to Child Sexual Abuse}

\begin{abstract}
Theodore P. Cross, Lisa M. Jones, Wendy A. Walsh, Monique Simone, David J. Kolko, Joyce Szczepanski, Tonya Lippert, Karen Davison, Arthur Cryns, Polly Sosnowski, Amy Shadoin, and Suzanne Magnuson
\end{abstract}

Children's Advocacy Centers (CACs) play an increasingly significant role in the response to child sexual abuse and other child maltreatment in the United States. First developed in the 1980s, CACs were designed to reduce the stress on child abuse victims and families created by traditional child abuse investigation and prosecution procedures and to improve the effectiveness of the response.

According to several experts (Fontana, 1984; Pence and Wilson, 1992; Whitcomb, 1992), child victims were subjected to multiple, redundant interviews about their abuse by different agencies, and were questioned by professionals who had no knowledge of children's developmental limitations or experience working with children. Child interviews would take place in settings like police stations that would further stress already frightened children. Moreover, the response was hampered because the multiple agencies involved did not coordinate their investigations, and children's need for services could be neglected.

CACs aimed to correct these problems by coordinating multidisciplinary investigation

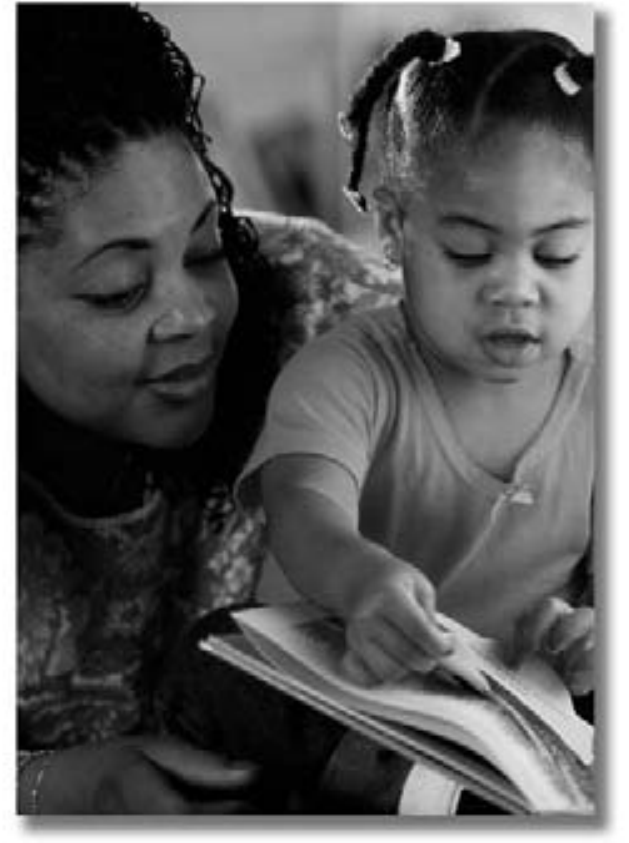

teams in a centralized, child-friendly setting; employing forensic interviewers specially trained to work with children; and assisting children and families in obtaining medical, therapeutic, and

\section{A Message From OJJDP}

Child sexual abuse investigations can place enormous stress on victims and their families. Prior to the 1980s, child abuse investigators had no model for conducting interviews and coordinating investigations.

The first Children's Advocacy Center (CAC) was established in 1986 to create a sensitive environment for child abuse interviews, provide victims and their families with medical and child protection services, and coordinate abuse investigations. The model has gained popularity in the past 20 years. As of 2006, the National Children's Alliance had certified more than 600 centers.

This Bulletin describes the findings of a study by researchers at the University of New Hampshire's Crimes Against Children Research Center that evaluated the effectiveness of the CAC model in four prominent Children's Advocacy Centers and nearby comparison communities. Findings demonstrate the important role these centers can play in advancing child abuse investigations and suggest ways in which the model could be improved in the future.

Investigators and service providers must make every effort to create a friendly environment for victims and their families. The information in this Bulletin is vital for improving the quality of service these centers provide to abuse victims and ensuring that offenders are prosecuted for their crimes. 
advocacy services. The CAC movement is based on the belief that the response system should focus on the needs of the child and family and is most effective when the skills of multiple agencies are coordinated (Chandler, 2000; see also Simone, Cross, Jones and Walsh, 2005).

The number of Children's Advocacy Centers in the United States has grown dramatically in the last 20 years. The first CAC was created in 1986 and by 1994 , there were 50 CACs established nationwide. As of 2006, the National Children's Alliance (NCA), the accrediting organization for CACs, reported more than 600 CACs. Four Regional Children's Advocacy Centers, supported by the Office of Juvenile Justice and Delinquency Prevention (OJJDP), help communities across the country to develop and improve CACs (OJJDP, n.d.). Thus, CACs are functioning to improve the experience of children and enhance the effectiveness of police, prosecutors, and other professionals in thousands of cases.

Despite the widespread growth and importance of CACs, however, the CAC model had not been rigorously evaluated. The field has lacked data about the actual impact of CACs. With funding from OJJDP, researchers have now completed a foursite evaluation of CACs that, for the first time, contrasts them with comparison communities that did not have a CAC.

This Bulletin presents an overview of the results. It examines how CACs affect forensic interviewing, child victim disclosures about abuse, children's receipt of medical exams and mental health services, prosecution and conviction of offenders,

removal of children from their homes, and family satisfaction with child abuse investigations. Key research findings include the following:

- Communities with CACs had greater law enforcement involvement in child sexual abuse investigations, more evidence of coordinated investigations, better child access to medical exams, more referrals for child mental health treatment, and greater caregiver satisfaction with the investigation process.

- CACs did not reduce the number of interviews children undergo: the vast majority of children in both CAC and comparison communities experienced only one or two forensic interviews.

- CACs and comparison communities had similar rates of prosecution and conviction of offenders. However, one
CAC filed more criminal charges than the community it was compared with (although it also had more dismissals), and another sentenced offenders to longer jail terms.

- In both CAC and comparison communities, 35 percent of children with a clinical need received mental health services. This data was limited to a subset of cases where caregivers consented to an interview.

$\checkmark$ Children in communities with CACs were removed from their homes more frequently than children in comparison communities.

- All the CACs in the study met the NCA standards; however, the structure and methods of the CACs differed. These differences could be used to initiate discussions about performance standards and best practices.

\section{Background}

CACs developed out of a larger movement in the United States to improve methods of investigating and responding to child abuse. Beginning in the 1980 s, child advocates voiced concerns that investigative and service agencies were not coordinating their activities, and investigation procedures were insensitive to children (see, for example, Whitcomb, 1992). Accordingly, the CAC philosophy incorporates several investigation reforms. Accrediting standards that NCA established (see National Children's Alliance, n.d.) require that CACs provide evidence of the following:

- A child-appropriate/child-friendly facility. CACs must provide a welcoming environment that is private and physically and psychologically safe. Typically this is geographically separate from police stations, child protective services (CPS), and courthouses. Facilities are designed to provide a child- and family-friendly environment for interviews and family meetings.

- A multidisciplinary investigation team and coordinated forensic interviews. A multidisciplinary team typically consists of law enforcement officers, CPS investigators, prosecutors, and mental health and medical professionals. The team members coordinate their response to increase the investigation's effectiveness and reduce stress for children. Methods may include interviews in which one trained forensic interviewer collects information from the child while multiple team members watch through a one-way mirror or closed-circuit television. The single interview informs multiple agencies, reducing the need for children to be interviewed more than once.

- Case reviews. In the weeks after the initial interview, the team reviews the case to give professionals further opportunities to refine planning, share new information, engage in team problem solving, and refer a child for additional services.

- Medical evaluation, therapeutic intervention, and victim advocacy services. CACs have formal links with medical professionals and arrange for medical examinations, as needed. Many have medical staff and facilities onsite. NCA membership standards require that CACs work with a victim's family to secure needed services, such as child psychotherapy and victims' advocacy services.

\section{Methods}

The Multi-Site Evaluation of Children's Advocacy Centers was funded by OJJDP and conducted by the Crimes against Children Research Center at the University

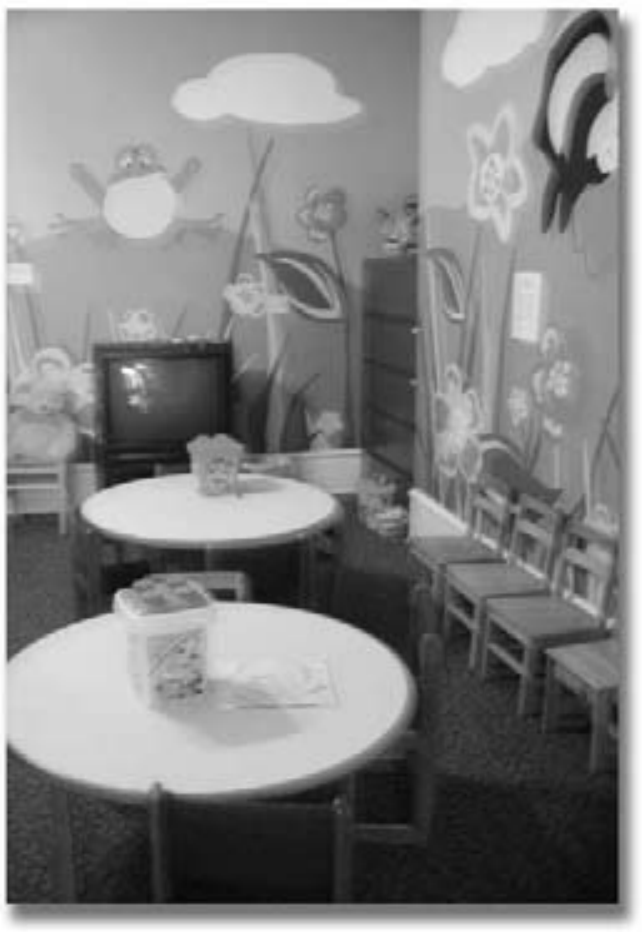

Courtesy of Dallas Children's Advocacy Center. The children's playroom provides a friendly and safe play space for those waiting for appointments. Volunteers designed and painted the walls. 
of New Hampshire in conjunction with research teams at each of the CACs participating in the study. To explore what happens in a case when a child has access to a CAC, the research team collected data from four CACs and comparison communities in the same state. These comparison communities did not have a local CAC. ${ }^{1}$

The four CACs chosen to participate were among the most experienced and longstanding CACs in the country. Because more experienced CACs were selected, this study may be more akin to an efficacy study, which examines the impact of an intervention under optimal conditions, than an effectiveness study, which studies the impact of an intervention under more typical conditions. Researchers enrolled cases in the study between December 2001 and December 2002. Data collection continued through December 2004. The researchers collected three types of data:

1) Case file data from case file records.

Research assistants at each of the sites extracted case file data from case records. These data included information about the victim, the alleged perpetrator, the victim's family, the alleged abuse, whether the victim disclosed the abuse, investigation, interviewing, services provided, whether the child was removed from the home, and whether the offender was charged and prosecuted.

2) Interview data from research interviews with children and nonabusive caregivers. The research team conducted interviews 3-4 months after the investigation to provide families' sufficient time to gauge the impact of the CACs and other agencies' involvement and to avoid burdening parents and children soon after the demands of an investigation. During research interviews, caregivers provided information on their experiences and satisfaction with the investigation, on services their families received as a result of the investigation, and on their child's emotional well-being. Interviewers asked children age 8 and older for their perspective of the investigation and for self-reports of their emotional well-being.

3) Descriptive, site-level data collected during site visits. Descriptive, site-level

1 For further information about the study, see Cross, et al.(in press), Jones et al. (in press), and Walsh et al. (in press)

\section{Research Sample}

The researchers collected case file data from a sample of 1,452 cases across the four research sites (784 Children's Advocacy Center (CAC) cases and $668 \mathrm{com}$ parison cases). CAC cases were randomly selected between December 2001 and December 2003. Researchers randomly selected comparison site cases from all police and child protective services (CPS) investigations of sexual or serious physical abuse initiated during the enrollment period.

Overall, 84 percent of cases involved sexual abuse. The four CACs and their comparison communities varied in the percentage of physical abuse cases in their samples. Because of differences in case characteristics and investigation procedures for sexual and physical abuse cases, only cases of reported sexual abuse were included in the analyses presented in this Bulletin (1,220 cases). Investigators invited caregivers involved in many of these cases to participate in research interviews, and 284 agreed. In 120 cases, investigators conducted research interviews with children who were age 8 and older (120 children).

Children's ages varied across CACs, from a median of 6.8 in Pittsburgh, PA, to a median of 13.3 in Huntsville, AL. Other variations across CACs included the percentage of adolescent offenders (6 percent to 40 percent), the percentage with multiple alleged offenders ( 8 percent to 23 percent), the percentage of cases with a CPS investigation (65 percent to 98 percent), and the percentage of allegations substantiated (42 percent to 70 percent). These ranges reflect differences in the role of CACs and the process by which cases are referred to CACs in each community (see Walsh, Jones, and Cross, 2003).

The CAC and comparison groups had several notable differences. CAC cases have more racially diverse victims than the comparison sample because of differences in the characteristics of the communities. The CAC cases also had a higher rate of more serious abuse allegations (incidents involving vaginal or anal penetration) and fewer allegations involving an offender within the victim's family. The researchers used statistical controls in analyses when they needed to account for pre-existing differences between CAC and comparison cases.

data included detailed information about a site's policy, protocols, and day-to-day operations.

\section{CAC Evaluation Findings}

Researchers collected information on an extensive number of variables to examine the many potential effects of CACs on investigation processes and outcomes. This Bulletin presents an overview of the effects that CACs have had on child abuse investigations. (See the table on page 7 for a summary of findings.) Detailed analyses of the findings are available in several comprehensive and outcomespecific papers: Cross et al., in press; Lippert et al., 2007, n.d.; Jones et al., 2006; Walsh et al., in press.

\section{CAC Characteristics}

While all the CACs met NCA standards and shared the same philosophy and essential capabilities, they varied considerably in many structures and processes (Walsh, Jones, and Cross, 2003). They differed in their organizational base (e.g., large children's hospital versus small, independent family services center), their stage or organizational development, their referral process (referrals based on a professional's judgement versus a standard protocol) and their specific emphasis (e.g., criminal justice versus human services).

\section{Investigations and Child Interviewing}

Improving investigation methods and child forensic interviews following allegations of child abuse is a central aim of CACs. This study measured different aspects of how investigations and child interviews were conducted.

Overall, communities with CACs showed more evidence of coordinated investigations than comparison communities (Cross et al., in press). CAC cases more often used multidisciplinary team interviews (28 percent of CAC cases versus 6 percent of comparison cases), videotaping of interviews (52 percent versus 17 percent), joint CPS-police investigations (81 percent versus 52 percent), and multidisciplinary 


\section{Participating Children's Advocacy Center Sites}

Criteria for selecting Children's Advocacy Center (CAC) sites to participate in this research required CACs to have-

- An active and well-established membership in the National Children's Alliance.

- An application that outlined a viable plan for collecting data from a comparison community.

- Adequate resources for undertaking the evaluation project.

Enough cases per year to supply an adequate sample size for planned statistical analyses.

Criteria for selecting comparison communities required these communities to have-

- A roughly equivalent number of sexual abuse cases as did CAC communities.

- A similar demographic makeup to CAC communities.

$\checkmark$ No existing CAC.

Participating sites include-

- The Dallas Children's Advocacy Center (DCAC), in Dallas, TX. The DCAC opened in 1991 as an independently located CAC. The Dallas Police Department played a central role in its development. A specialized police child abuse unit is housed onsite along with a special unit of Dallas County Child Protective Services. To attain a comparable sample size, two cities in Dallas County-Garland and Irving - served as comparison communities for DCAC.

- The Dee Norton Lowcountry Children's Center, Inc. (LCC) in Charleston, SC. LCC was officially established as an independently located CAC in 1991. It has close ties with a number of community agencies that work with children. Oconee and Anderson Counties served as the comparison communities for LCC.

- The National Children's Advocacy Center (NCAC), Huntsville, AL. Created in 1985, NCAC was the Nation's first CAC. The center still plays a leadership role in the field. NCAC has onsite law enforcement, CPS, prosecution, mental health, medical, and educational professionals. Morgan County, AL, served as the comparison community for NCAC.

- The Pittsburgh Child Advocacy Center (PCAC), Pittsburgh, PA. PCAC had one of the earliest medical child abuse programs in the Nation, dating back to the 1960s. PCAC functions as a department of Children's Hospital of Pittsburgh. Armstrong County, PA, served as the comparison community for the PCAC.

case reviews (56 percent versus 7 percent). CACs were more likely to have police involvement in interviewing the child in CPS child sexual abuse investigations than comparison communities (55 percent versus 43 percent).

Although coordination was stronger overall in CACs, the methods used to coordinate investigations varied, and not every CAC used every available method. Furthermore, certain comparison communities frequently used one or more specific coordination methods, occasionally more than their corresponding CAC community.

All CACs in the study provided separate, private, and comfortable facilities specially designed for interviewing children, and 81 percent of child interviews in the CAC sample were conducted in these facilities. Other locations were used for the CAC sample either because other agencies conducted interviews prior to referral to the CAC or CAC staff conducted interviews offsite (e.g., in a hospital emergency room). The comparison community interviews were distributed across a range of different locations, including CPS offices (22 percent), schools (19 percent), police stations (18 percent), homes (16 percent), and other locations (24 percent).

Contrary to researchers' hypotheses, children interviewed in CACs and comparison communities underwent about the same number of interviews. Many children in both communities had one interview, and 95 percent had no more than two. Similarly, 85 percent of CAC cases and comparison cases had just one interviewer.

One possible explanation for this finding is historical change. Practice texts and guides have warned against the problems of redundant interviews for nearly 20 years (see, for example, American Professional Society on the Abuse of Children, 2002; Whitcomb, 1992), and professionals probably have begun to heed these warnings over the years. These findings suggest that lack of coordination in child abuse investigations may be a bigger problem than excessive interviewing of child victims.

\section{Disclosure}

The steps that CACs take to reduce stress on children who have been abused may make it easier for the victims to disclose the abuse in the forensic interview. Disclosure during a forensic interview is often not the child's first statement about the abuse. The majority of the allegations in $\mathrm{CAC}$ and comparison communities arose because children first told a parent, counselor, or other person. Disclosure in the forensic interview is important for several reasons. Disclosure allows investigators to make an accurate decision about allegations, to prepare legal and child protection interventions if needed, and to explore the impact of the abuse on the child.

Researchers compared CAC and comparison communities on disclosure at the forensic interview. The analysis was limited to children and youth who investigators concluded were abused based on the variety of evidence gathered in the investigation. Children in comparison communities disclosed slightly more often than those in CAC communities (78 percent versus 71 percent), but this difference was not statistically significant. Most of the children interviewed had already disclosed the abuse in their home or community and may well have been prepared to tell the truth in the interview regardless of setting.

A child's age, both at the time of abuse and at the time of the forensic interview, was the best explanation for the fact that 27 percent of children did not disclose (see Lippert et al., 2007). The cognitive immaturity of young children may mean they cannot easily comprehend, remember, and provide a coherent report of the 
abuse, a limitation that interviewing techniques and a comfortable setting may not be able to counter.

\section{Medical Exams}

CACs strive to improve access to forensic medical exams. Medical examinations can be an important part of the response to suspected child sexual abuse. They increase the likelihood of timely medical care for the child and provide information to support legal decisionmaking. Many professionals recommend that all reported child sexual abuse victims have a medical evaluation (Adams et al., 2006; De Jong and Rose, 1989; Finkel and De Jong, 2001; Heger, 1996; Kerns, Terman, and Larson, 1994).

The percentage of children who had medical examinations was significantly greater in CACs (48 percent) than in comparison communities (21 percent). (For a full description of forensic medical findings, see Walsh et al., in press). The hospitalbased CAC in Pittsburgh, PA, however, had a significantly greater percentage of cases receiving medical exams (95 percent) than the other CACs (37 percent to 49 percent). Nonetheless, the range for the comparison samples was lower, from 13 percent to 35 percent. Even when other variables such as a child's age, physical injury, and alleged penetration are taken into consideration, children interviewed at CACs were twice as likely to receive a medical exam.

The difference in medical examinations between the CAC and comparison communities was particularly pronounced in cases where the sexual abuse did not involve penetration. CAC cases not thought to involve penetration were four times more likely to receive exams than similar cases in comparison communities.

\section{Mental Health Services}

Sexual abuse victims are at high risk for emotional and behavioral problems (Kendall-Tackett, Williams, and Finkelhor, 1993). The CAC model strives to improve victim access to mental health services. CACs referred a higher proportion of victims to mental health services (72 percent) than comparison communities (31 percent). CACs directly provided mental health services for 30 percent of their cases. In the remaining cases, the CAC referred the child to community and private mental health practitioners.

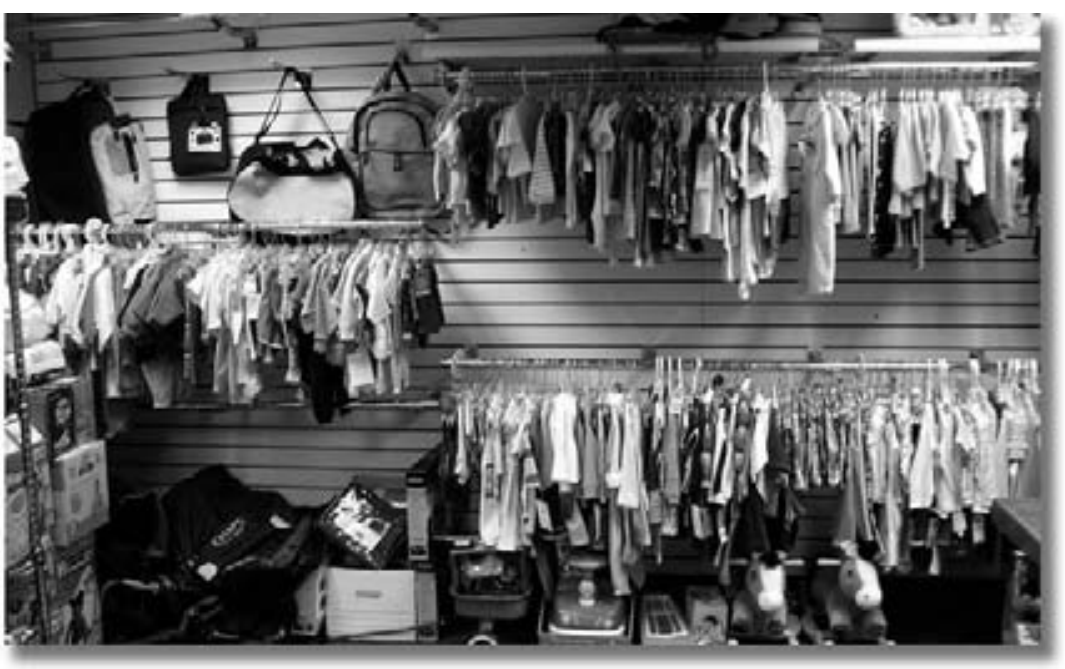

Courtesy of Dallas Children's Advocacy Center. The "clothes closet" provides emergency clothing, personal care items, or special items for children in need.

However, interviews with caregivers in the CAC study found no difference in rates of access to child mental health services in $\mathrm{CAC}$ and comparison sites. Thirty-five percent of caregivers in both CAC sites and comparison communities reported that their children had received individual mental health treatment as a result of the investigation. Across $\mathrm{CAC}$ and comparison cases in which caregivers were interviewed, 70 percent of "high-risk" children, defined as those scoring in the clinical range on the Child Behavior Checklist (CBCL, Achenbach, and Rescorla, 2001), received mental health services either because of the investigation or a continuation of previous services.

There are a number of possible reasons that data from caregiver interviews showed substantially greater referral rates for mental health services at CACs than comparison sites but no difference in service access rates. The difference in referral rate could have been due to an artifact of poor documentation in the comparison communities. Alternately, better referral rates at CACs may not translate into actual follow through for therapy, which may depend more on the initiative of caregivers. In addition, caregivers who were interviewed could have represented a select sample. The research interview sample was demographically similar to the noninterview sample (Jones et al., in press) but unmeasured differences may have existed between the two groups. These differences, for example, might include the type of abuse the victims faced and their openness to psychotherapy.

\section{Child Protection}

Investigations of child sexual abuse occasionally lead to the CPS agency removing a child from the home, if the agency finds that the child is in danger of further maltreatment. An investigation through a CAC could increase removal rates because of more thorough investigation procedures and more aggressive protection strategies, or it could decrease removal rates if work with families and nonoffending caregivers increased safety levels in the home.

Among the 830 cases accepted for investigation, CPS removed 12 percent of sexual abuse victims from their homes. The percentage was significantly greater in the CAC communities (17 percent) than in comparison communities (4 percent). In most of these cases, the child was temporarily placed in a relative's home. The difference between CAC and comparison samples was consistent across the four research sites. Even when other variables were considered (such as child age and race, substantiation, caregiver support, and whether the offender lived with the victim), the odds of placement outside the home were 2.1 times greater in CAC cases.

CAC involvement may have led to more frequent child placement for a variety of reasons. Differences in the types of cases that CACs and comparison communities received are possible explanations for this finding. Other possible reasons include the thoroughness of risk assessment, access to resources, or differences in the decisionmaking process. CAC cases involved police more often than comparison cases, and some evidence suggests that children are removed from abusive 
situations more frequently when police are involved in the investigation. Two studies (Shireman, Miller, and Brown, 1981; Cross, Finkelhor, and Ormrod, 2005) found that children were removed from their homes more often when police participated in the cases, though the effect in the latter study only pertained to physical abuse cases and was not statistically significant. Yet, placement happened more often in CAC communities than in comparison communities even in Pittsburgh and Charleston where CACs lacked strong police presence. The data compiled in this study are insufficient to assess removal decisionmaking processes and the adequacy of removal decisions.

\section{Criminal Justice Outcomes}

Improving criminal justice outcomes for child sexual abuse cases helps protect children and is a critical goal for many CACs. However, effecting change in criminal charges and convictions could be difficult for CACs. Many factors can influence these outcomes, including State law and a variety of processes among police, prosecutors, and the courts. Moreover, it is difficult to measure the effect CACs may have on the criminal justice system because of the relatively small percentage of sexual abuse cases that make their way through the entire criminal justice process (Cross et al., 2003). This evaluation found few indications that CAC communities prosecuted sexual abuse cases more effectively than comparison communities, except in two sites where the CACs had strong involvement with police and prosecutors.

\section{Referring cases to court and filing} criminal charges. In the Dallas site, criminal charges were filed at a rate of 55 percent in both the CAC and comparison community sample. However, the Dallas CAC and both comparison communities were all served by the Dallas County District Attorney.

At the CAC in Huntsville, AL, all cases were referred to the prosecutor by virtue of a multidisciplinary team meeting process. In the comparison community, only 25 percent of cases were referred to the prosecutor. The CAC in Huntsville also showed greater rates of filing criminal charges than its comparison community. However, the $\mathrm{CAC}$ also had a higher rate of dismissing cases once charged than the comparison community. The other participating CACs and their comparison communities had no differences in the rates at which they filed criminal charges.
Offender confession. An analysis of the Dallas and Huntsville CACs found that 37 percent of offenders confessed at CACs compared to 29 percent in comparison communities, but this finding was not statistically significant (see Lippert-Luikart, et al., n.d.). The Pittsburgh and Charleston centers had too few cases in which charges were filed to permit analysis.

Conviction rates and sentencing. Across CACs, the percentage of charged cases leading to conviction ranged from 67 percent to 82 percent; these percentages were not significantly different from the three comparison communities for which data were available, where the percentage of charged cases convicted ranged from 75 percent to 84 percent.

An exception involved the Dallas CAC and its comparison communities. Although these communities convicted offenders at a similar rate; convictions from the CAC community occurred more often at trial than in the comparison communities, while convictions in the comparison communities occurred more frequently through a guilty plea than in the CAC community. The CAC and comparison communities in Dallas had similar rates of offenders who went to jail, but offenders in CAC sites received longer sentences (an average 331 months versus 157 months), with cases that were convicted at trial receiving much longer sentences.

\section{Families' Experiences With the Investigation}

Almost all CAC programs are intended to improve the experience for children and families. This outcome might be considered one of the primary tests of the agencies' success. Researchers asked caregivers and children about their satisfaction with investigator supportiveness, communicativeness, and skill in collecting evidence and about the comfort and safety families felt during forensic interviews (Jones et al., in press).

Overall, caregiver satisfaction with the investigation was moderately high across samples, but satisfaction was greater in the CAC samples than in the comparison communities. When asked about satisfaction with the investigation process, 70 percent of caregivers in CAC communities reported high levels of satisfaction versus 54 percent of the caregivers from comparison communities. Additionally, 83 percent of caregivers who worked with CACs reported high satisfaction with the inter- view procedures compared with 54 percent of the comparison sample. These positive findings for CACs held even when accounting for other variables (e.g., caregiver support for the child, agency involvement in the case, and case outcomes).

Compared with caregivers, children in $\mathrm{CAC}$ and control samples generally had fewer differences in satisfaction with the investigation (Jones et al., in press). However, answers to one question suggest that children in CAC cases may feel less scared during interviews. Although children rated their experiences as mostly positive, a minority of children (15 to 20 percent) from both $\mathrm{CAC}$ and comparison communities described being unsatisfied with the interview experience. For example, they felt worse after talking with investigators or felt investigators did not understand children or explain sufficiently what was going to happen next.

\section{Community-Level Outcomes}

CACs intervene at the level of individual children and families, but they also help their communities as a whole. The CACs in the study provided a number of services to their communities: training to other professionals, consultation to other agencies and departments with which they worked, child abuse prevention activities, and community education on child maltreatment. The CACs are regarded as community leaders and experts in the area of child abuse. Moreover, each CAC brought in private dollars for child maltreatment services that would not otherwise be available through other child serving agencies.

The impact of CACs on their communities, although potentially noteworthy, could not be fully measured in this study. Nevertheless, the number of CAC activities and amount of money raised, often on behalf of universally-supported practices (e.g., adequate reporting of child maltreatment, mental health services for child victims), suggests that CACs do have a favorable impact on communities. This impact should be included in assessments of their value.

\section{The Impact of CACs}

In this study, CAC cases demonstrated several apparent advantages over comparison communities. Multiagency investigations of child sexual abuse were more likely to be coordinated and more likely to involve police. Children were 


\section{Table 1: Results From the Multi-Site Evaluation of Children's Advocacy Centers (CACs)}

Outcome

Finding

\section{Investigations and Interviews}

Joint police and child protective service

investigations

Team forensic interviews (interviews with two or more observers)

Police involvement in interviews

Case review

Forensic interview location

Number of child forensic interviews
81 percent of investigations in CACs were joint police and child protective services investigations compared with 52 percent in comparison communities.

28 percent of $\mathrm{CAC}$ cases used team interviewing compared with 6 percent in comparison communities.

55 percent of CAC interviews involved police compared with 43 percent of comparison community interviews.

56 percent of CAC cases had multidisciplinary case review, compared with 7 percent in comparison communities.

83 percent of CACs held interviews in center facilities designed for interviewing children, while 75 percent of interviews in comparison communities were conducted in child protective agencies, schools, police stations, or children's homes.

85 percent of cases in both CACs and comparison communities involved only one child forensic interview.

Over 70 percent of children disclosed at forensic interviews in both CACs and comparison communities, with no statistically significant difference between the two.

\section{Services}

Medical exams

Mental health services

\section{Case Outcomes}

Child protective service

Offender confession

Criminal justice

\section{Family Satisfaction With Investigations}

Caregiver satisfaction

Child satisfaction
48 percent of children in $\mathrm{CAC}$ cases received a forensic medical exam, compared with 21 percent in comparison communities.

72 percent of CAC cases documented a referral for mental health services sample of interviewed caregivers reported that 35 percent of children received mental health services as a result of the investigation.

17 percent of CAC sample children were removed from their homes compared with 4 percent in comparison communities, among cases that CPS accepted for investigation.

37 percent of offenders confessed in CACs versus 29 percent in comparison communities. This difference was not statistically significant.

67 percent to 84 percent of charges resulted in convictions in both CACs and comparison communities. One CAC filed more criminal charges than its comparison community (but also dismissed more), and another secured longer jail sentences for offenders. These CACs had strong police and prosecutor involvement in cases.

70 percent of caregivers from CACs expressed high satisfaction with the services they received versus 54 percent in comparison communities.

Approximately 75 percent to 80 percent of children in both CACs and comparison communities expressed moderate to high satisfaction with the investigation. versus 31 percent in comparison community cases. Across groups, a sub- 
more likely to receive referrals for forensic medical evaluations and mental health services, although analyses could not identify referrals that were not recorded in agency records. Nonabusive caregivers reported a higher average level of satisfaction, both with child interviewing and with the investigation as a whole. Children tended to report feeling less scared during CAC interviews.

However, no evidence suggested that children were subjected to multiple forensic interviews in either CACs or comparison communities.

Other similarities between CAC and comparison communities are harder to explain. CACs did not affect whether children thought to have been sexually abused disclosed the abuse in a forensic interview. This finding may stem from factors like prior disclosure in the community and child age. The fact that parents reported that their children received mental health services at the same rate in CAC and comparison communities could indicate that a mental health referral does not translate into followthrough on services. Another possibility is that the group of caregivers who participated in interviews were more likely to seek mental health services than other caregivers in both the $\mathrm{CAC}$ and comparison communities.

Most CACs did not differ from comparison communities on criminal justice variables (filing charges, offender confessions, and convictions). Establishing a CAC in a community does not guarantee effective prosecution for child abuse cases. Police and prosecutors must be substantially involved in and committed to the mission of prosecuting child abuse and the CAC method for CACs to help bring about the successful prosecutions of offenders. CAC communities with better criminal justice outcomes than comparison communities generally had involved and committed police and prosecutors.

Many different factors contribute to successful prosecution of child abuse. These include effective methods of gathering corroborative evidence (Vieth, 1999) and special training of prosecutors (see Vieth, Bottoms, and Perona, 2005). Criminal justice professionals need to improve these investigation and prosecution methods (Lanning, 1996; Vieth, 1999) to impact child abuse prosecution.

\section{Limitations of the Research}

These findings represent only a limited sample of agencies and may not be generally applicable to all CACs. Some key CAC models and types were not represented among the four CACs in the evaluation. For example, the need for adequate sample sizes meant that smaller CACs from suburban or rural communities were not included. Some CACs are based in district attorneys' offices and may have more of a criminal justice focus, but these were not represented in this research because none responded to researchers' call for proposals.

CAC and comparison communities may have differed in ways that could not be accounted for. For instance, two CACs in the study received cases based on the discretion of professionals or parents, while the comparison organizations received every case in their community that met their referral criteria. CACs that receive cases on a discretionary basis may tend to receive cases that are more difficult or confusing that other professionals cannot handle on their own. This limitation is difficult to avoid altogether without randomly assigning cases to CAC and comparison groups.

Additionally, CACs can be difficult to assess when national practice standards are still being developed. For example, this study tested whether CACs had an advantage in facilitating medical exams but had no standardized way to assess when medical exams were actually needed.
CACs provide good settings for research on how best to respond to child abuse and create such national practice standards, in part, because they are mostly private organizations unencumbered by the barriers to research that exist in police, prosecutor, and child protective service agencies.

\section{Recommendations}

CACs have achieved national prominence. Their rapid growth suggests that CACs have a philosophy that attracts community leaders and energizes child advocates. CACs also have the advantage of being well-organized; they are currently the only multidisciplinary investigation model that has a national membership board and a formal accreditation process. However, prominence means greater scrutiny. The evaluation findings suggest that CACs can take several steps to improve their effectiveness. Key implications of the results for CAC advocates are discussed below.

CACs should serve as models for systematically incorporating ongoing research into child abuse investigation practices. CACs should aim to use research findings more extensively to inform their membership standards and establish benchmarks or measurable goals for their work. The results of this study suggest a number of useful changes. For example:

- When promoting their programs, CACs should emphasize their skills in improving coordination, facilitating services, and working with families. Without supporting data, they should

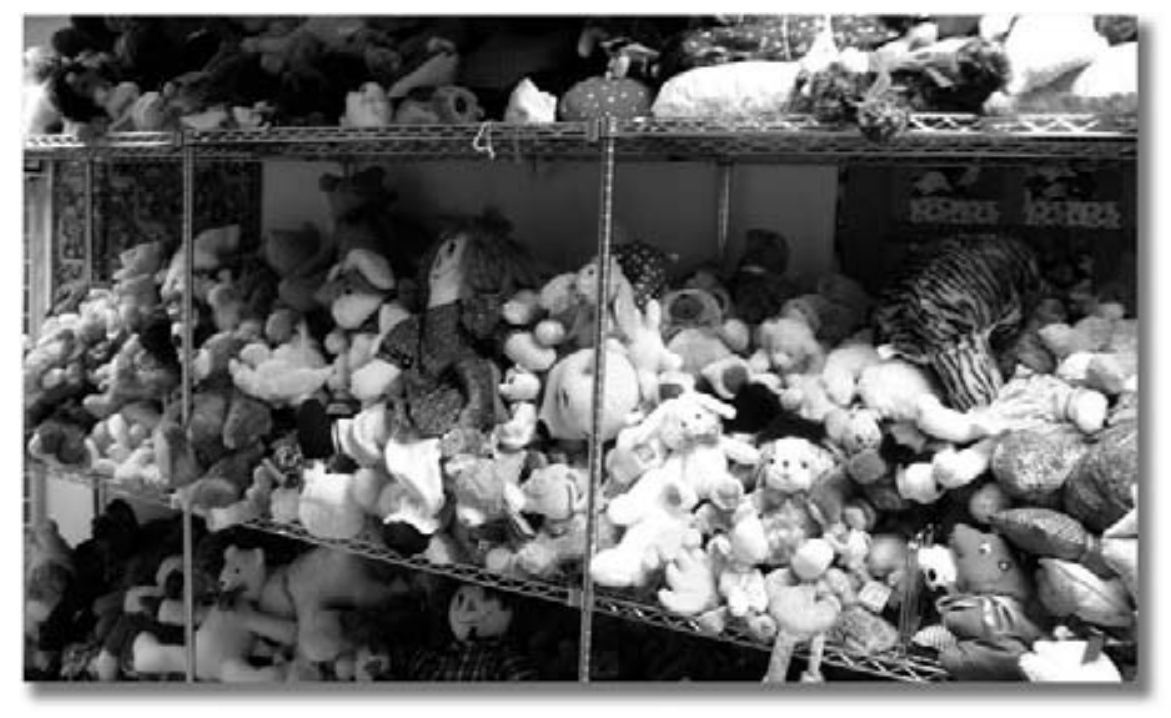

Courtesy of Dallas Children's Advocacy Center. A stuffed bear or doll is waiting for each child at the end of his or her first visit to the center. 
not claim that they currently reduce the number of child interviews relative to other investigative agencies.

- CACs could take the lead in establishing benchmarks of medical service to ensure that child victims who need them receive exams from trained medical professionals. Medical exams were provided more frequently in CAC samples than in comparison samples, but rates still varied across agencies.

$\checkmark$ CACs should make greater efforts to track service referral and receipt, and increase access to mental health services. Although the data from this study suggest that CACs provide more mental health referrals, few data are available on how many children receive services (but see Lippert, Favre et al., in press).

- CACs should address complaints from children and caregivers. For example, although most caregivers and children expressed satisfaction with CACs, in open-ended responses, nonabusive caregivers frequently described wanting more frequent communication about the case. Some children from all communities were dissatisfied with the interview experience. Improving children's comfort should be a high priority for all investigators.

Much of the impact of CACs is the cumulative effect of a host of specific methods, such as forensic interviewing, forensic medical examinations, multidisciplinary teams, and trauma-focused psychotherapy. Researchers involved in the study suggest that CAC program improvement will depend on the child abuse professional and research fields making further progress in developing specific intervention methods. They recommend that CACs adopt the best practices that research supports (see Jones et al., 2005) and participate in research themselves to develop best practices.

Although CACs have improved child abuse investigations, professionals should not become too attached to the "brand name" of CACs and should recognize that other programs also use many of the same interventions and perform many of the same functions. Some capable programs have chosen not to enroll in the National Children's Alliance.

CACs and the child professional field should explore the diversity in CAC models and give greater thought to which specific methods should vary across CACs and which should be constant. The
National Children's Alliance suggests that "no single model for an ideal multidisciplinary program exists, because each community's approach must reflect its unique characteristics" (Chandler, 2000: 7; see Walsh, Jones, and Cross, 2003). However, more evaluation and research is needed to distinguish between variation in models that is appropriate because of differences in community needs and variation that instead represents differences in the quality of services.

\section{Conclusion}

The difficulties that child abuse victims face are enormous. CACs are an important mechanism for society to address these difficulties. This research suggests that CACs can help coordinate agencies and involve police with child protective services, and can facilitate such needed services as medical exams. Nonoffending caregivers also favor CACs over traditional services. However, CACs are not a panacea for the difficulties of child abuse investigation, and prosecuting offenders or caring for victims will always require the commitment and skill of community health professionals, child protective services, and law enforcement.

CACs' experience in bringing professionals together, their attention to training, their ties to the private and public sectors, and their lack of entrenchment in bureaucracy position them to help lead the child abuse professional field. Although CACs have existed since the 1980s, the components and goals of the CAC model are still evolving. Research and program improvements can help CACs find ever better ways to help children tell their stories and receive the response that they need.

\section{References}

Achenbach, T.M. and Rescorla, L.A. 2001. Manual for ASEBA School-Age Forms and Profiles. Burlington, VT: University of Vermont, Research Center for Children, Youth, and Families.

Adams, J.A., Kaplan, R., Starling, S.P., Mehta, N., Finkel, M., Botash, A., et al. (In press). Guidelines for medical care of children who may have been sexually abused. Journal of Pediatric and Adolescent Gynecology.

American Professional Society on the Abuse of Children. 2002. Investigative interviewing in cases of alleged child abuse. Practice Guidelines Series. Charleston, SC:

APSAC.
Chandler, N. 2000. Best Practices for Establishing a Children's Advocacy Center (Third edition). Washington, DC: National Children's Alliance.

Cross, T.P., Finkelhor, D., and Ormrod, R. 2005. Police involvement in child protective services investigations. Child Maltreatment 10(3):224-244.

Cross, T.P., Jones, L.M., Walsh, W.A., Simone, M., and Kolko, D. In press. Child forensic interviewing in children's advocacy centers: Empirical data on a practice model. Child Abuse and Neglect.

Cross, T.P., Walsh, W.A., Simone, M., and Jones, L.M. 2003. Prosecution of child abuse: A meta analysis of rates of criminal justice decisions. Trauma, Violence, and Abuse 4(4):323-340.

De Jong, A.R. and Rose, M. 1989. Frequency and significance of physical evidence in legally proven cases of child sexual abuse. Pediatrics 84(6):1022-1026.

Finkel, M.A., and De Jong, A.R. 2001. Medical findings in child sexual abuse. Child Abuse: Medical Diagnosis and Management. Philadelphia, PA: Lippincott, Williams, and Wilkins.

Fontana, V.J. 1984. When systems fail: Protecting the victim of child sexual abuse. Children Today 13(4):14-18.

Heger, A. 1996. Twenty years in the evaluation of the sexually abused child: Has medicine helped or hurt the child and the family? Child Abuse and Neglect 20(10): 893-897.

Jones, L.M., Cross T.P., Walsh, W.A., and Simone, M. 2005. Criminal investigation of child abuse: The research behind "best practices." Trauma, Violence and Abuse 6(3):254-268.

Jones, L.M., Cross, T.P., Walsh, W.A., and Simone, M. In press. Do Children's Advocacy Centers improve families' experiences of child abuse investigations? Child Abuse and Neglect.

Kendall-Tackett, K.A., Williams, L.M., and Finkelhor, D. 1993. Impact of sexual abuse on children: A review and synthesis of recent empirical studies. Psychological Bulletin 113(1):164-180.

Kerns, D.L., Terman, D.L., and Larson, C.S. 1994. The role of physicians in reporting and evaluating child sexual abuse cases. The Future of Children 4(2):119-134. 
Lanning, K.V. 1996. Criminal investigation of sexual victimization of children. In The APSAC handbook on child maltreatment, edited by J. Briere, L.Berliner, J.A. Bulkley, C. Jenny, and T. Reid. Thousand Oaks, CA: Sage, Publications, Inc.

Lippert, T., Cross, T.P., Jones L.M., and, Walsh, W.A. 2007. Telling interviewers about sexual abuse: Predictors of child disclosure at forensic interviews. Submitted for publication. Dallas, TX: Dallas Children's Advocacy Center.

Lippert T., Cross, T.P., Jones L.M., and, Walsh, W.A. 2007. Confessing sexual abuse to investigators: Predictors for offenders at child advocacy centers and comparison sites. In preparation. Dallas, TX: Dallas Children's Advocacy Center.

Lippert, T., Favre, T., Alexander, M.C. and, Cross, T.P. (In press). Families who begin and decline therapy for children who are sexually abused. Child Abuse and Neglect.
National Children's Alliance, n.d. National Children's Alliance Standards for Accredited Members. Retrieved September 12, 2006.

From the Web: http://nca-online.org/ pages/page.asp?page_id=4032.

Office of Juvenile Justice and Delinquency Prevention, n.d. Program Summary: Children's Advocacy Centers. Retrieved May 1, 2007, from http://ojjdp.ncjrs.org/programs/ ProgSummary.

Pence, D.M. and Wilson, C.A. 1994. Reporting and investigating child sexual abuse. The Future of Children 4:70-83.

Shireman, J., Miller, B., and Brown, H.F. 1981. Child welfare workers, police and child placement. Child Welfare 55(6): 413-422.

Simone, M., Cross, T.P., Jones, L.M., and Walsh W. 2005. "Children's advocacy centers: Understanding the impact." In Victimization of Children and Youth: Patterns of Abuse, Response Strategies. edited by K. Kendall-Tackett and S. Giacomoni. Kingston, NJ: Civic Research Institute.
Vieth, V. 1999. When a child stands alone: The search for corroborating evidence. American Prosecutors Research Institute Update, 12. No. 6. Alexandria, VA: American Prosecutors Research Institute.

Vieth, V., Bottoms, B., and Perona, A. 2005. Ending Child Abuse: New Efforts in Prevention, Investigation, and Training. Binghamton, NY: The Haworth Press.

Walsh, W.A., Cross, T.P., Jones, L.M., Simone, M., and Kolko, D. In press. Who receives a medical exam? Children's advocacy centers and comparison communities. Child Abuse and Neglect.

Walsh, W., Jones, L.M., and Cross, T. 2003. Children's Advocacy Centers: One philosophy, many models. APSAC Advisor, 15(3):3-7.

Whitcomb, D. 1992. When the Victim is a Child: Issues for Judges and Prosecutors. 2d ed. Report for the National Institute of Justice, Office of Justice Programs, U.S. Department of Justice. Washington, DC: National Institute of Justice. 


\section{Acknowledgments}

This bulletin was written by:

Theodore P. Cross

University of New Hampshire and RTI International

Lisa M. Jones, Wendy A. Walsh, and Monique Simone

University of New Hampshire

David J. Kolko and Joyce Szczepanski

University of Pittsburgh School of Medicine

\section{Tonya Lippert and Karen Davison}

Dallas Children's Advocacy Center

Arthur Cryne and Polly Sosnowski

Dee Norton Lowcountry Children's Center

Amy Shadoin and Suzanne Magnuson

National Children's Advocacy Center

Thanks to the staff and leadership of the Dallas Children's Advocacy Center for their pictures and participation in the project.

\section{Share With Your Colleagues}

Unless otherwise noted, OJJDP publications are not copyright protected. We encourage you to reproduce this document, share it with your colleagues, and reprint it in your newsletter or journal. However, if you reprint, please cite OJJDP and the authors of this Bulletin. We are also interested in your feedback, such as how you received a copy, how you intend to use the information, and how OJJDP materials meet your individual or agency needs. Please direct your comments and questions to:
This Bulletin was prepared under grant numbers 1999-JP-FX-1101, 01-JN-FX-0009, and 2002-JW-BX-0002 from the Office of Juvenile Justice and Delinquency Prevention (OJJDP), U.S. Department of Justice.

Points of view or opinions expressed in this document are those of the author(s) and do not necessarily represent the official position or policies of OJJDP or the U.S. Department of Justice.

The Office of Juvenile Justice and Delinquency Prevention is a component of the Office of Justice Programs, which also includes the Bureau of Justice Assistance, the Bureau of Justice Statistics, the National Institute of Justice, and the Office for Victims of Crime. 
U.S. Department of Justice

Office of Justice Programs

Office of Juvenile Justice and Delinquency Prevention

Washington, DC 20531

Official Business

Penalty for Private Use $\$ 300$
PRESORTED STANDARD

POSTAGE \& FEES PAID

DOJ/OJJDP

PERMIT NO. G-91 